EDITORIAL Rev Chil Salud Pública 2015; Vol 19 (2): 129

\title{
EL EDITOR SE DESPIDE ${ }^{(\mathbf{i})}$
}

\section{THE EDITOR TAKES A BOW}

Más razones que las que caben en la cabeza de un alfiler me han llevado a un hospital de la Patagonia con un nuevo baúl de esperanzas. El precio más alto a pagar en este desplazamiento es dejar este trabajo editorial. Muchas cosas se pueden efectuar a distancia, pero hacer una revista -como el amores presencial.

Como alumno, amigo y polemista del nuevo editor, Miguel Kottow, tengo la certeza de que nuevos rumbos y perspectivas esperan a la $R C H S P$. Miguel ha tenido además la gentileza de honrarme asignándome la responsabilidad de editar una sección. En tal condición, mi despedida se torna incluso una semidespedida.

Pero, la Revista Chilena de Salud Pública no es uno u otro editor, sino un equipo múltiple, diverso, democrático, intelectualmente vivo e inspirado. En julio del 2011 casi no existía y hoy podemos sentirnos orgullosos de este puñado de compañeros: Miguel, Jorge, Jana, Katherine, Verónica, Mauricio, Florencia, César, Carlos. Y de los que se integran hoy. Sin la confianza de Óscar, Giorgio y Patricio este equipo tampoco habría sido posible.

La Revista es fundamentalmente un horizonte intelectual: la convicción de que la salud pública requiere un diálogo entre medicina y ciencias sociales. En las ambigüedades de esta frase no oculto diferencias conceptuales que seguramente se expresarán en nuevos rumbos a partir de hoy, sino que intento pergeñar valores compartidos que prevalecen.

También estos años han hecho del papel y de la estética un contenido de la Revista. El papel no es una pantalla y las ideas viven de mejor manera entintadas reflejando una luz tercera. El cuidado del estilo, la belleza de la tipografía y la ocupación por el diseño, son los mejores frutos de nuestra alianza con Ocho Libros.

Y finalmente, la calidad de los artículos. La Revista se ha desarrollado como un ser vivo, con subespecializaciones de células, tejidos, órganos y sistemas. Creo que hemos mejorado, pero nuestra disciplina tiene dificultades. Intentamos expresar la frontera en salud pública. El delirio de los indexadores ha conspirado contra ese propósito, en alguna proporción. Pero es nuestra frontera la que requiere reformulaciones.

Agradezco a las centenas de personas que hicieron posible estos cuatro años. Especialmente a quienes escribieron, corrigieron, leyeron o gestionaron. A todos aquellos que me devolvieron una sonrisa cuando puse un ejemplar en sus manos y cinco o seis peticiones.

Para ellos y para ustedes, queridos lectores, que dan vida y sentido a nuestro trabajo, desde la Patagonia estas dos líneas de Pound a manera de despedida:

\section{What thou lovest well remains the rest is dross}

Yuri Carvajal

Editor

Revista Chilena de Salud Pública

ycarvajal@med.uchile.cl (i). A partir del próximo número de la Revista (Volumen 19, núm. 3) el Editor de esta publicación será Miguel Kottow. Otros cambios en el equipo editorial incluyen asignación de responsabilidades por secciones de la revista y la designación de un nuevo editor asociado. En el próximo número se detallarán estas modificaciones. 